\title{
Depression after surgery for acoustic neuroma
}

Göran C Blomstedt, Heikki Katila, Markus Henriksson, Anita Ekholm, Juha E Jääskeläinen, Ilmari Pyykkö

\begin{abstract}
The purpose of this study was to establish the frequency and pattern of depressive disorders after surgery for acoustic neuroma, and to look for associations. Twenty seven patients with acoustic neuroma underwent thorough psychiatric assessment before surgery and at three and 12 months after surgery. Three patients had a depressive disorder in the preoperative assessment. Of the remaining 24 patients, nine (38\%) had a depressive disorder at the three month check up. Deterioration of hearing was the only postoperative detriment associated with a depressive disorder $(P=0.024)$. All nine patients with a depressive disorder were women $(P=0.001)$, giving them a $69 \%$ incidence. None of the patients without preoperative depression required inpatient treatment for depressive disorder, but three patients out of nine still had a depressive disorder 12 months after surgery.
\end{abstract}

(F Neurol Neurosurg Psychiatry 1996;61:403-406)

Keywords: acoustic neuroma; surgical complications; depressive disorders

Depression after surgery for acoustic neuroma is usually acknowledged by clinicians, but never listed along with other typical postoperative problems. The aim of this prospective study was to assess the size of the problem: how common is depression after acoustic neuroma surgery, how severe a problem is it, and is it associated with other complications?

\section{Patients and methods}

The study comprised all consecutive patients, beginning 3 October 1990 and ending 16 October 1991, operated on for an acoustic neuroma in the department of neurosurgery, Helsinki University Central Hospital. There were 27 patients: 12 men, 15 women, median age 49 (range 17 to 64 ) years. The median extrameatal maximum diameter of the tumours was 1.5 (range 0.7 to 6.5 ) $\mathrm{cm}$. A retrosigmoidal approach was used in 24 patients and a translabyrinthine approach in three. Two patients had a shunt inserted 14 and eight days before tumour removal.

\section{PSYCHIATRIC ASSESSMENT}

One of three experienced psychiatrists trained in descriptive diagnostics and in consultationliaison psychiatry, had a comprehensive face to face psychiatric interview with the patient, on admission, and at three and 12 months after the operation. The interview covered the patient's everyday life and behaviour, personal history, social situation and life events, any possible psychiatric symptomatology, medical treatment, and alcohol and drug use. We assigned the diagnoses of mental disorders following the DSM-III-R, and the severity of mood disorders more specifically with the Montgomery-Åsberg depression scale. ${ }^{12}$ Psychosocial stress six to 12 months before the diagnosis of acoustic neuroma was rated with the severity of psychosocial stressors scale (in DSM-III-R, axis IV). ${ }^{1}$ The scale ranged from none $(=1)$ to catastrophic $(=6)$. The current psychological, social, and occupational functioning was assessed with the global assessment of functioning scale (GAF in DSM-III-R, axis V), ranging from gross impairment $(=1)$ to good functioning in all areas $(=90) .^{1}$ For cross tabulations we dichotomised the result into unimpaired or slightly impaired (65 or more) versus clearly impaired $(<65)$.

\section{OTHER ASSESSMENT}

Facial function was determined from video recordings with a modified House and Brackmann scale, assessing forehead, eye, and mouth regions separately (excellent function $=1$, paralysis $=6$ ).

Hearing assessment was based on pure tone threshold average (PTA $=$ mean of thresholds for 500,1000 , and $2000 \mathrm{~Hz}$ ), and speech discrimination score (SDS = percentage of appreciated words in a series voiced at optimal volume). For PTA $30 \mathrm{~dB}$ or less was good $(=0), 31-69 \mathrm{~dB}$ moderate $(=1)$, and $70 \mathrm{~dB}$ or more poor $(=2)$; for SDS $70 \%$ or better was good $(=0), 31-69 \%$ moderate $(=1)$, and $30 \%$ or less poor $(=2)$.

Tinnitus was assessed with a questionnaire, asking the patient to recall the tinnitus before 
Depression in relation to other findings in 27 consecutive patients operated on for an acoustic neuroma

\begin{tabular}{|c|c|c|c|c|c|c|c|c|c|c|c|c|c|c|c|c|c|c|c|c|}
\hline \multicolumn{11}{|c|}{ On admission } & \multicolumn{10}{|c|}{3 Month check up } \\
\hline $\operatorname{Sex}$ & Age & Size & $D g$ & $P T A$ & $S D S$ & Tinn & $R Q$ & Stress & $G A F$ & $M-A$ & $D g$ & $P T A$ & $S D S$ & Change & Tinn & $R Q$ & $H \mathcal{E} B$ & Hache & $G A F$ & $M-A$ \\
\hline $\begin{array}{l}F \\
F \\
F \\
F \\
F \\
F \\
F \\
F \\
F\end{array}$ & $\begin{array}{l}47 \\
45 \\
50 \\
57 \\
38 \\
43 \\
50 \\
49 \\
52\end{array}$ & $\begin{array}{l}1.5 \\
1.5 \\
1.0 \\
2.5 \\
1.5 \\
2.0 \\
1.0 \\
2.0 \\
1.5\end{array}$ & Anx & $\begin{array}{r}12 \\
38 \\
17 \\
27 \\
22 \\
27 \\
112 \\
37 \\
18\end{array}$ & $\begin{array}{r}100 \\
92 \\
76 \\
100 \\
90 \\
50 \\
0 \\
100 \\
90\end{array}$ & $\begin{array}{l}2 / 2 \\
2 / 1 \\
0 / 0 \\
0 / 0 \\
3 / 2 \\
0 / 0 \\
0 / 0 \\
2 / 3 \\
0 / 0\end{array}$ & $\begin{array}{l}1.4 \\
2 \\
1.9 \\
0.9 \\
1.4 \\
1.7 \\
2.3 \\
1.6 \\
1.7\end{array}$ & $\begin{array}{l}1 \\
5 \\
3 \\
3 \\
2 \\
3 \\
1 \\
1 \\
3\end{array}$ & $\begin{array}{l}70 \\
85 \\
80 \\
80 \\
90 \\
75 \\
75 \\
75 \\
75\end{array}$ & $\begin{array}{r}11.5 \\
1.5 \\
2.0 \\
2.5 \\
1.0 \\
4.5 \\
3.0 \\
8.0 \\
10.5\end{array}$ & $\begin{array}{l}\text { Maj } \\
\text { MMaj } \\
\text { MMaj } \\
\text { Adj } \\
\text { Adj } \\
\text { Adj } \\
\text { Adj } \\
\text { Adj } \\
\text { Adj }\end{array}$ & $\begin{array}{r}120 \\
85 \\
28 \\
70 \\
33 \\
120 \\
120 \\
120 \\
120\end{array}$ & $\begin{array}{r}0 \\
0 \\
0 \\
0 \\
92 \\
0 \\
0 \\
0 \\
0\end{array}$ & $\begin{array}{r}-100 \\
-\quad 75 \\
-\quad 50 \\
-100 \\
-\quad 25 \\
-75 \\
-\quad 0 \\
-75 \\
-100\end{array}$ & $\begin{array}{l}2 / 2 \\
2 / 1 \\
2 / 1 \\
2 / 0 \\
2 / 1 \\
0 / 0 \\
1 / 1 \\
2 / 2 \\
2 / 2\end{array}$ & $\begin{array}{l}? \\
1.7 \\
? \\
1.5 \\
1.2 \\
2.2 \\
1.5 \\
1.3 \\
2.5\end{array}$ & $\begin{array}{l}4 / 4 / 4 \\
1 / 1 / 1 \\
1 / 2 / 3 \\
5 / 5 / 4 \\
1 / 1 / 1 \\
4 / 5 / 4 \\
5 / 4 / 4 \\
1 / 1 / 2 \\
1 / 1 / 1\end{array}$ & $\begin{array}{l}1 \\
3 \\
0 \\
0 \\
1 \\
0 \\
0 \\
0 \\
0\end{array}$ & $\begin{array}{l}65 \\
60 \\
80 \\
80 \\
80 \\
75 \\
65 \\
60 \\
75\end{array}$ & $\begin{array}{r}8 \cdot 0 \\
8 \cdot 0 \\
0 \cdot 0 \\
2 \cdot 0 \\
6 \cdot 0 \\
1 \cdot 5 \\
8 \cdot 5 \\
10 \cdot 5 \\
6 \cdot 0\end{array}$ \\
\hline Mean & 48 & $1 \cdot 6$ & & 34 & 33 & $1 / 0.9$ & $1 \cdot 7$ & $2 \cdot 4$ & 78 & $4 \cdot 9$ & & 91 & 10 & -67 & $1 \cdot 7 / 1 \cdot 1$ & $1 \cdot 7$ & $2 \cdot 6 / 2 \cdot 7 / 2 \cdot 7$ & 0.6 & 71 & $5 \cdot 6$ \\
\hline $\begin{array}{l}F \\
F \\
F \\
F \\
M \\
M \\
M \\
M \\
M \\
M \\
M \\
M \\
M \\
M \\
M\end{array}$ & $\begin{array}{l}56 \\
26 \\
61 \\
56 \\
36 \\
61 \\
46 \\
40 \\
50 \\
59 \\
17 \\
48 \\
44 \\
45 \\
54\end{array}$ & $\begin{array}{l}3.5 \\
1 \cdot 2 \\
4 \cdot 0 \\
1.5 \\
4 \cdot 0 \\
1.5 \\
1 \cdot 0 \\
0.7 \\
2.0 \\
3.0 \\
3.0 \\
1.5 \\
1.5 \\
6.0 \\
4.0\end{array}$ & $\begin{array}{l}\text { Org } \\
\text { Sch }\end{array}$ & $\begin{array}{r}67 \\
17 \\
120 \\
38 \\
53 \\
62 \\
8 \\
55 \\
30 \\
82 \\
120 \\
73 \\
13 \\
70 \\
120\end{array}$ & $\begin{array}{r}50 \\
100 \\
0 \\
50 \\
50 \\
0 \\
90 \\
32 \\
64 \\
0 \\
0 \\
0 \\
100 \\
96 \\
0\end{array}$ & $\begin{array}{l}0 / 0 \\
3 / 3 \\
2 / 2 \\
0 / 0 \\
2 / 2 \\
0 / 0 \\
0 / 0 \\
0 / 0 \\
0 / 0 \\
2 / 3 \\
0 / 0 \\
3 / 2 \\
0 / 0 \\
1 / 0 \\
2 / 2\end{array}$ & $\begin{array}{l}1.0 \\
0.9 \\
1.1 \\
1.5 \\
1.5 \\
1.6 \\
1.2 \\
1.2 \\
1.8 \\
1.2 \\
1.4 \\
1.0 \\
2.2 \\
1.1 \\
2.0\end{array}$ & $\begin{array}{l}1 \\
1 \\
3 \\
1 \\
1 \\
1 \\
1 \\
1 \\
1 \\
3 \\
4 \\
1 \\
1 \\
2 \\
1\end{array}$ & $\begin{array}{l}85 \\
80 \\
85 \\
90 \\
85 \\
85 \\
80 \\
90 \\
65 \\
85 \\
75 \\
90 \\
90 \\
30 \\
75\end{array}$ & $\begin{array}{r}4 \cdot 0 \\
2 \cdot 0 \\
2 \cdot 5 \\
1 \cdot 5 \\
2 \cdot 0 \\
0 \cdot 0 \\
5 \cdot 5 \\
0 \cdot 0 \\
4 \cdot 0 \\
0 \cdot 0 \\
2 \cdot 0 \\
3 \cdot 0 \\
4 \cdot 0 \\
16 \cdot 0 \\
1 \cdot 0\end{array}$ & Sch & $\begin{array}{r}120 \\
23 \\
120 \\
120 \\
120 \\
120 \\
35 \\
120 \\
120 \\
120 \\
120 \\
120 \\
120 \\
120 \\
120\end{array}$ & $\begin{array}{r}0 \\
100 \\
0 \\
0 \\
0 \\
0 \\
96 \\
0 \\
0 \\
0 \\
0 \\
0 \\
0 \\
0 \\
0\end{array}$ & $\begin{array}{r}50 \\
0 \\
0 \\
-\quad 50 \\
-\quad 50 \\
-\quad 25 \\
-\quad 25 \\
-\quad 50 \\
-\quad 75 \\
0 \\
0 \\
0 \\
-100 \\
-\quad 50 \\
0\end{array}$ & $\begin{array}{l}2 / 2 \\
2 / 1 \\
1 / 1 \\
0 / 0 \\
2 / 2 \\
0 / 0 \\
0 / 0 \\
0 / 0 \\
2 / 2 \\
1 / 1 \\
0 / 0 \\
1 / 1 \\
2 / 2 \\
1 / 0 \\
2 / 2\end{array}$ & $\begin{array}{l}1.8 \\
2.4 \\
? \\
? \\
? \\
1.4 \\
1.3 \\
1.7 \\
1.8 \\
1.5 \\
1.7 \\
? \\
? \\
1.9 \\
1.4\end{array}$ & $\begin{array}{l}4 / 4 / 3 \\
2 / 1 / 2 \\
1 / 1 / 2 \\
1 / 1 / 1 \\
6 / 6 / 6 \\
5 / 5 / 5 \\
1 / 1 / 1 \\
1 / 1 / 1 \\
1 / 1 / 1 \\
2 / 2 / 2 \\
1 / 1 / 1 \\
6 / 6 / 6 \\
1 / 1 / 1 \\
1 / 1 / 1 \\
6 / 6 / 6\end{array}$ & $\begin{array}{l}0 \\
0 \\
0 \\
0 \\
0 \\
0 \\
0 \\
0 \\
0 \\
2 \\
0 \\
0 \\
2 \\
0 \\
0\end{array}$ & $\begin{array}{l}85 \\
90 \\
80 \\
80 \\
85 \\
80 \\
90 \\
85 \\
80 \\
80 \\
90 \\
85 \\
90 \\
70 \\
80\end{array}$ & $\begin{array}{l}0.0 \\
0.0 \\
2.5 \\
3.5 \\
0.5 \\
2 \cdot 0 \\
0.5 \\
0.5 \\
2.5 \\
4.5 \\
3.0 \\
1.5 \\
2.0 \\
3.5 \\
5.0\end{array}$ \\
\hline Mean & 47 & $2 \cdot 6$ & & 62 & 13 & $1 / 0.9$ & $1 \cdot 4$ & $1 \cdot 5$ & 79 & $3 \cdot 2$ & & 108 & 13 & -32 & $1 \cdot 1 / 0 \cdot 9$ & $1 \cdot 7$ & $2 \cdot 6 / 2 \cdot 5 / 2 \cdot 6$ & $0 \cdot 3$ & 83 & $2 \cdot 1$ \\
\hline $\begin{array}{l}F \\
F \\
M\end{array}$ & $\begin{array}{l}49 \\
65 \\
36\end{array}$ & $\begin{array}{l}1 \cdot 0 \\
2 \cdot 0 \\
6.5\end{array}$ & $\begin{array}{l}\text { MMaj } \\
\text { Dep } \\
\text { SMaj }\end{array}$ & $\begin{array}{r}120 \\
65 \\
27\end{array}$ & $\begin{array}{r}0 \\
60 \\
100\end{array}$ & $\begin{array}{l}3 / 3 \\
2 / 2 \\
2 / 0\end{array}$ & $\begin{array}{l}1.4 \\
1.6 \\
2.3\end{array}$ & $\begin{array}{l}3 \\
4 \\
4\end{array}$ & $\begin{array}{l}60 \\
60 \\
50\end{array}$ & $\begin{array}{l}12.5 \\
12.5 \\
18.5\end{array}$ & $\begin{array}{l}\text { Anx } \\
\text { MajR }\end{array}$ & $\begin{array}{l}120 \\
120 \\
120\end{array}$ & $\begin{array}{l}0 \\
0 \\
0\end{array}$ & $\begin{array}{r}0 \\
-\quad 50 \\
-100\end{array}$ & $\begin{array}{l}1 / 2 \\
0 / 0 \\
2 / 1\end{array}$ & $\begin{array}{l}1 \cdot 3 \\
1 \cdot 7 \\
?\end{array}$ & $\begin{array}{l}5 / 6 / 5 \\
1 / 1 / 1 \\
6 / 6 / 6\end{array}$ & $\begin{array}{l}1 \\
0 \\
0\end{array}$ & $\begin{array}{l}80 \\
70 \\
65\end{array}$ & $\begin{array}{l}3.5 \\
6.0 \\
6.5\end{array}$ \\
\hline Mean & 50 & $3 \cdot 2$ & & 71 & 33 & $2 \cdot 3 / 1 \cdot 7$ & $1 \cdot 8$ & $3 \cdot 7$ & 57 & $14 \cdot 5$ & & 120 & 0 & -50 & $1 / 1$ & 1.5 & $4 / 4 \cdot 3 / 4$ & $0 \cdot 3$ & 72 & $5 \cdot 3$ \\
\hline
\end{tabular}

Size = largest extrameatal tumor diameter; PTA = pure tone average; SDS = speech discrimination score; RQ = Romberg quotient; $H \& B=\mathrm{House}$ and Brachmann (forehead/eye region/mouth): $1=$ normal, $2=$ perceptible abnormality, $3=$ moderate disability, $4=$ severe disability, $5=$ noticeable movement or tonus, $6=$ paralysis; tinn $=$ tinnitus (loudness/distress): $0=$ none, $1=$ slight, $2=$ moderate, $3=$ severe; hache $=$ subjective headache: $0=$ normal, $1=$ slight discomfort, 2 $=$ moderate, $3=$ severe; stress = evaluation of psychosocial stressors 6-12 months before acoustic neuroma diagnosis: $1=$ none, $6=$ catastrophic (DSM-III-R axis IV); GAF (global assessment of functioning) = current psychosocial, social, and occupational functioning: $1=$ gross impairment, $90=$ good functioning in all areas (DSM-III-R axis V); M-A = Mongomery-Asberg, a depressions scale with 10 items each ranged 0 to $3 ; \mathrm{Dg}=$ diagnosis of current mental disorder in accordance with DSM-III-R; depressive disorders: MMaj = moderate major depression, Dep = depressive disorder NOS, AMaj = severe major depression, Maj = major depression, $\mathrm{Adj}=$ adjustment disorder with depressive mood, MajR = major depression in partial remission, Dth = dysthymia. Other psychiatric diagnosis: Anx = anxiety sion, Adj = adjustment disorder with depressive mood, MajR = major depression in partial remission, Dth $=$ dysthymia. Other psychiatric diagnosis: Anx $=$ anxiety
disorder NOS, org = organic mood disorder; Sch = paranoid schizophrenia in remission; change $=$ change in hearing, calculated with formula (see text); ? = not

the operation, at three months, and at 12 months after the operation. The grading for loudness was none $(=0)$; slight, perceivable in silence $(=1)$; moderate, perceivable despite everyday sounds $(=2)$; severe, always present even despite loud noise $(=3)$. The grading of distress was none $(=0)$; slightsometimes on one's mind $(=1)$; moderatedistressing especially if tired, but not hampering performance of interesting tasks $(=2)$; severe-unbearable $(=3)$.

Postural stability was assessed from measuring swaying $(\mathrm{cm} / \mathrm{s})$, eyes closed and eyes open, on a force platform and calculating the Romberg quotient ( $R Q=$ ratio of swaying with eyes closed to that with eyes open). The higher the $R Q$ the more dependent is the patient on visual information: $1.0-1.2$ excellent $(=0), 1 \cdot 3-1 \cdot 6$ normal $(=1), 1 \cdot 7-2 \cdot 0$ moderate $(=2)$, and $>2 \cdot 0$ poor $(=3)$.

Headache assessment was: no abnormal headache $(=0)$; slight $(=1)$; moderate-at times disturbing but responding well to pain killers $(=2)$; and disabling headache $(=3)$.

\section{ASSESSMENT OF ASSOCIATIONS WITH}

DEPRESSIVE DISORDERS

We compared symptoms or functions in the group of nine patients with a postoperative depressive disorder in the first three-month period (omitting the three patients with a depressive disorder in the preoperative assessment) to the group without ( 15 patients). We also compared the change in symptoms or functions in the groups as:
Change $=$

\begin{tabular}{c} 
(preoperative function - \\
postoperative function) $\times 100$ \\
\hline best possible preoperative function - \\
worst possible postoperative function
\end{tabular}

Facial function, hearing, and tinnitus were described by more than one variable and these were added up for the above calculation (see table regarding change in hearing).

We tested the differences between the groups by Mann-Whitney $U$ test or Fisher's exact test, and considered a probability level of $P<0.05$ as significant.

\section{Results}

\section{PSYCHIATRIC DISORDERS}

On admission we assigned psychiatric diagnoses for eight patients, three of which were depressive conditions (table).

At three months we diagnosed a psychiatric disorder in 12 patients and a depressive disorder in 10 (table). In four patients the depressive disorder had partially remitted before the check up, but the history of symptoms in the postoperative period clearly warranted the diagnosis. Antidepressant medication was instituted for one patient. None required treatment in a mental hospital at this stage.

At 12 months we diagnosed a psychiatric disorder in seven patients: a depressive disorder in six, of whom three had had a depressive disorder also at the three-month check up. In this phase one patient, already with a depres- 


\begin{tabular}{|c|c|c|c|c|c|c|}
\hline \multicolumn{4}{|c|}{12 Month check up } & \multirow[b]{2}{*}{ Hache } & \multirow[b]{2}{*}{$G A F$} & \multirow[b]{2}{*}{$M-A$} \\
\hline$D g$ & Tinn & $R Q$ & $H \mathcal{E} B$ & & & \\
\hline \multirow{7}{*}{ Maj } & $2 / 1$ & $1 \cdot 0$ & $3 / 2 / 4$ & 2 & 70 & $11 \cdot 0$ \\
\hline & $2 / 1$ & $2 \cdot 3$ & $1 / 1 / 1$ & 3 & 85 & 1.0 \\
\hline & $2 / 1$ & 1.9 & $1 / 2 / 3$ & 0 & 90 & 0.0 \\
\hline & $1 / 0$ & $1 \cdot 1$ & $5 / 3 / 3$ & 1 & 90 & 0.0 \\
\hline & $1 / 0$ & 1.0 & $1 / 1 / 1$ & 1 & 85 & 4.5 \\
\hline & $0 / 0$ & $2 \cdot 0$ & $3 / 3 / 3$ & 0 & 90 & 0.0 \\
\hline & $1 / 1$ & 1.0 & $5 / 2 / 4$ & 0 & 80 & 0.0 \\
\hline \multirow{11}{*}{$\begin{array}{l}\text { Dth } \\
\text { Dth }\end{array}$} & $2 / 2$ & $1 \cdot 7$ & $1 / 1 / 2$ & 0 & 75 & $7 \cdot 0$ \\
\hline & $2 / 2$ & 1.5 & $1 / 1 / 1$ & 1 & 70 & $12 \cdot 5$ \\
\hline & $1 \cdot 5 / 0 \cdot 9$ & 1.5 & $2 \cdot 3 / 1 \cdot 8 / 2 \cdot 4$ & 0.9 & 82 & $4 \cdot 0$ \\
\hline & $3 / 2$ & 1.4 & $3 / 2 / 3$ & 0 & 90 & 0.0 \\
\hline & $2 / 2$ & 1.0 & $2 / 1 / 2$ & 1 & 90 & 1.0 \\
\hline & $1 / 1$ & 1.0 & $1 / 1 / 1$ & 0 & 90 & 0.5 \\
\hline & $1 / 1$ & $1 \cdot 3$ & $1 / 1 / 1$ & 0 & 90 & 1.0 \\
\hline & $2 / 2$ & $2 \cdot 3$ & $6 / 6 / 6$ & 0 & 85 & 1.5 \\
\hline & $0 / 0$ & $2 \cdot 2$ & $5 / 5 / 5$ & 0 & 85 & 0.0 \\
\hline & $0 / 0$ & $1 \cdot 7$ & $1 / 1 / 1$ & 0 & 90 & 0.5 \\
\hline & $0 / 0$ & 1.4 & $1 / 1 / 1$ & 0 & 90 & $1 \cdot 0$ \\
\hline \multirow[t]{4}{*}{ Adj } & $2 / 2$ & $2 \cdot 1$ & $1 / 1 / 1$ & 0 & 75 & 8.0 \\
\hline & $1 / 1$ & $1 \cdot 0$ & $1 / 2 / 3$ & 1 & 80 & $2 \cdot 0$ \\
\hline & $0 / 0$ & $1 \cdot 0$ & $1 / 1 / 1$ & 0 & 90 & 1.0 \\
\hline & $2 / 2$ & 1.0 & $5 / 3 / 4$ & 1 & 90 & 0.5 \\
\hline \multirow[t]{2}{*}{ Adj } & $2 / 2$ & $2 \cdot 6$ & $1 / 1 / 1$ & 2 & 80 & 6.0 \\
\hline & $1 / 0$ & $2 \cdot 3$ & $1 / 1 / 1$ & 0 & 90 & 0.5 \\
\hline \multirow[t]{2}{*}{ Sch } & $2 / 2$ & $1 \cdot 0$ & $6 / 6 / 6$ & 0 & 80 & 3.0 \\
\hline & $1 \cdot 3 / 1 \cdot 1$ & $1 \cdot 6$ & $2 \cdot 4 / 2 \cdot 2 / 2 \cdot 5$ & 0.3 & 86 & $1 \cdot 8$ \\
\hline \multirow{4}{*}{ Maj } & $1 / 2$ & $1 \cdot 0$ & $4 / 3 / 3$ & 1 & 85 & $2 \cdot 0$ \\
\hline & $0 / 0$ & $1 \cdot 2$ & $1 / 1 / 1$ & 1 & 40 & $21 \cdot 0$ \\
\hline & $3 / 2$ & $?$ & ? & $?$ & 80 & $5 \cdot 0$ \\
\hline & $1 \cdot 3 / 1 \cdot 3$ & $1 \cdot 1$ & $2 \cdot 5 / 2 / 2$ & $1 \cdot 0$ & 68 & $9 \cdot 3$ \\
\hline
\end{tabular}

sive disorder in the preoperative assessment, needed psychiatric inpatient treatment.

\section{ASSOCIATION BETWEEN DEPRESSIVE DISORDERS AND OTHER FACTORS}

Because postoperative depression was the issue, we omitted from group comparison patients with a depressive disorder in the preoperative assessment. Of the remaining 24 patients nine had a depressive disorder at three months, and five at 12 months; three had a depressive disorder both at three and 12 months.

For comparison between the group with depressive disorder (DD group) and without depressive disorder (no DD group) we chose the three-month check up. All nine in the DD group were women, versus four of the 15 in the no DD group $(P=0.001)$. Compared with the no DD group, the DD group had a slightly smaller median tumour size $(1.5 \mathrm{~cm} v$ $2.0 \mathrm{~cm} ; P=0 \cdot 190)$, roughly the same median age (49 years $v 46$ years; $\mathrm{P}=0.905$ ), slightly higher preoperative psychosocial stress score (axis IV; $P=0.065$ ), and similar psychological, social, and occupational functioning (GAF; $P=0 \cdot 180)$. Preoperative hearing was better in the DD group: good in five patients versus three in the no DD group, whereas one patient was deaf or had poor hearing in the DD group against six in the no DD group. The quality of moderate hearing was also better in the depressive disorder group; all three patients with moderate hearing had either good quality PTA or SDS, versus one of six in the no DD group (PTA, $P=0.06$; SDS, $P=$ 0.052).

At three months eight out of nine in the DD group were deaf or had poor hearing, one had moderate hearing; in the no DD group 13 out of 15 were deaf, one had moderate, and one good hearing (PTA, $\mathrm{P}=0.136$; $\mathrm{SDS}, \mathrm{P}=$ $0 \cdot 795)$. However, the relative hearing loss, or change in hearing (see formula), was significantly greater in the DD group $(P=0.024$; table). Comparing the groups at three months for tinnitus $(P=0.324)$, facial function $(P=$ $0.804)$, Romberg quotient $(P=0.731)$, or headache $(P=0.294)$ did not show any significant differences. Nor did comparing the groups for the preoperative versus postoperative change in tinnitus $(P=0.396)$, facial function $(P=0.804)$, or headache $(P=$ $0 \cdot 294)$. The change of Romberg quotient tended to be less favourable in the no DD group $(P=0.087)$.

\section{Discussion}

Over the years we have seen several patients with severe depression after surgery for acoustic neuroma. Two patients in our series in the late 1970 s and early 1980 s committed suicide after removal of an acoustic neuroma. To date, there are no published reports on the frequency of depression after surgery for acoustic neuroma. Among severely ill patients diagnosable depressive disorders are common, and hearing loss and tinnitus are reported to be associated with depression. ${ }^{34}$ An attempt to show a specific causal relation between depression and surgery for acoustic neuroma would require a very large population of patients with acoustic neuromas. Ultimately final proof would require the first assessment to be done before the diagnosis of acoustic neuroma. We therefore decided, at this stage, to describe the psychiatric findings in an unselected series of patients with acoustic neuroma, and to search for associations between depressive disorders and complications and symptoms.

PRESENT SERIES

The present study specifically focused on well defined depressive disorders. We analysed all consecutive patients operated on for an acoustic neuroma during a 12 month period. We interviewed and evaluated each patient, using careful clinical judgement in discriminating symptoms, and DSM-III-R criteria as recommended for studies of depression associated with somatic illness. ${ }^{5}$ Because postoperative depression was the object of the study we excluded patients with a depressive disorder in the preoperative assessment from comparison aiming at detecting contributing factors. We did the grouping, based on the three month check up, into those with a depressive disorder and those without. There was a strong correlation with sex $(P=0.001)$ : the rate of postoperative depression was $69 \%$ for women but zero for men. Hearing loss after surgery was common in both groups, but because preoperative hearing was much better in the DD group comparing the change in hearing in the 
groups reached significance $(P=0.024)$. Presumably in the no DD group, with worse hearing already before surgery, the psychological adaptation to the loss of hearing may have been largely processed. Contrary to our expectations, tinnitus did not associate with depression, a discrepancy possibly caused by selection: patients seeking medical advice specifically for tinnitus are probably those with the most severe symptoms.

COURSE OF DEPRESSION

During the 12 month follow up no patient attempted suicide, and only one patient, who already had a depressive disorder before surgery, needed psychiatric inpatient treatment. Three of the nine patients with postoperative depression still had symptoms after 12 months. The psychiatric interviews in this study included supportive psychotherapeutic and psychoeducational elements, which, with the fact that the depression was taken seriously, may have had a beneficial and possibly prophylactic effect. Thus depressive disorders may be more common in other acoustic neuroma series, and the course may be less favourable. The tendency for depression to recur may amplify the importance of postoperative depressive disorders. ${ }^{6}$

1 American Psychiatric Association. Diagnostic and statistical manual of mental disorders. 3rd ed, revised. Washington DC: APA, 1987

2 Montgomery SA, Åsberg MA. A new depression scale designed to be sensitive to change. Br $\mathcal{f}$ Psychiatry 1979; 134:382-9.

3 Keitner GI, Ryan CE, Miller IW, Kohn R, Epstein NB. 12month outcome of patients with major depression and comorbid psychiatric or medical illness. Am $\mathcal{F}$ Psychiatry 1991;148:345-50.

4 McKenna L, Hallam RS, Hinchcliffe R. The prevalence of psychological disturbance in neuro-otology outpatients. Clin Otolaryngol 1991;16:452-6. 5 Fava GA. Depression in medical settings. In: Paykel ES,
ed. Handbook of affective disorders. London: Churchill Livingstone, 1992;667-85.

6 Keller MB. Depression: a long-term illness. Br f Psychiatry 1994;165(suppl 26):9-15. 